\title{
Equine cyathostomins: a review of biology, clinical significance and therapy Susan Corning*
}

\author{
Address: Fort Dodge Animal Health Italy, Via G. Amendola, 8, 40121 Bologna, Italy \\ Email: Susan Corning* - cornins@fdah.com \\ *Corresponding author
}

Published: 25 September 2009

Parasites \& Vectors 2009, 2(Supp| 2):SI doi:I0.I |86/I756-3305-2-S2-SI

This article is available from: http://www.parasitesandvectors.com/content/2/S2/SI

(C) 2009 Corning; licensee BioMed Central Ltd.

This is an Open Access article distributed under the terms of the Creative Commons Attribution License (http://creativecommons.org/licenses/by/2.0), which permits unrestricted use, distribution, and reproduction in any medium, provided the original work is properly cited.

\begin{abstract}
The small strongyles of horses, also known as cyathostomins, are considered the most prevalent and pathogenic parasites of horses today. The clinical syndrome of larval cyathostominosis which occurs as a result of mass emergence of inhibited stages has a high fatality rate despite the best standard of care given to affected horses. Management of the challenge level of cyathostomins to prevent the syndrome is preferable. Many different management programmes have been tried over the past two decades, with mixed success. Programmes have relied heavily on repeated use of anthelmintic treatments throughout the life of a horse. The widespread incidence of resistance to certain anthelmintics is reducing these options. An understanding of the biology of cyathostomins, risk factors for infection and appropriate strategic use of still effective anthelmintics is essential for the future management of this parasite group. This review highlights the necessity to use currently available anthelmintics that are appropriately suited to the biology of cyathostomins, and to maintain heir efficacy through an appropriate treatment strategy.
\end{abstract}

Small strongyles (Nematoda, Strongylida) or "cyathostomins" have been reported from horses worldwide. They are highly prevalent in equine populations regardless of climatic or management differences, and seem equally at home in horses in the tropics as in temperate or cold climates [1-3]. Concerns have been raised in many aspects of managing cyathostomin challenges in horses, ranging from increasing prevalence, resistance to anthelmintic drugs and how to prevent and manage the clinical syndrome of larval cyathostominosis. There are more than 50 species of cyathostomins recognised $[1,4]$ with some 10 species reported to be the most prevalent. They are today the most common and pathogenically significant parasite to affect horses around the world $[3,5,6]$.

Although much has been written about the prevalence [3,5,7-13] and dangers of these nematodes, a brief review of their biology and clinical significance can be useful in understanding the need for developing appropriate and effective anthelmintic strategies to best protect horses from these highly pathogenic invaders. 


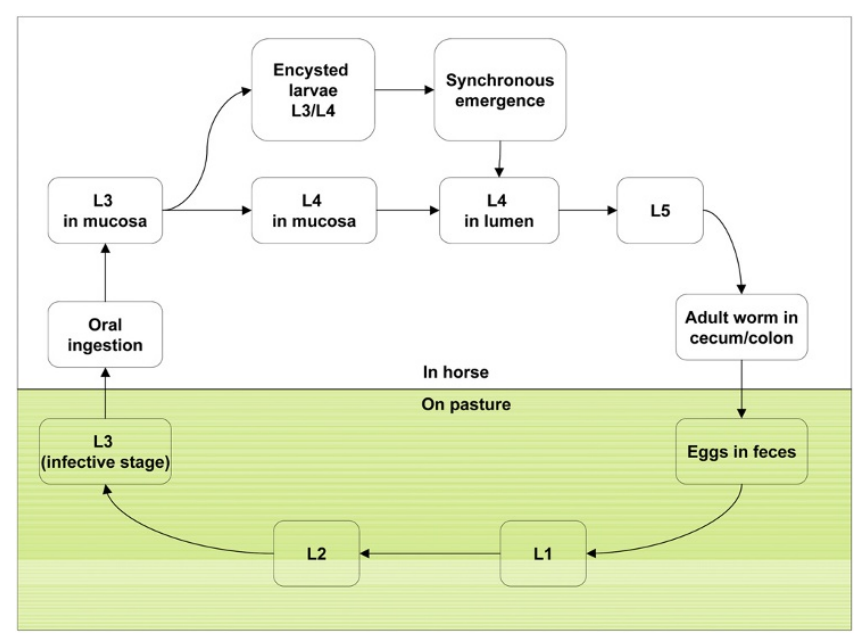

Figure I

Life cycle of cyathostomins.

\section{Life-cycle and epidemiology}

Cyathostomins are commonly known as "small redworms" due to the fact that they are usually less than $2.5 \mathrm{~cm}$ in length, and sometimes appear more red than white in colour. Like many other nematodes, cyathostomins have a direct lifecycle, with no intermediate host.

A schematic description of the life cycle of cyathostomins is presented in Figure 1. Cyathostomins enter the intestine at the third larval stage (L3) which has developed from eggs passed through the faeces onto pasture land. Once ingested by the horse, they continue their maturation and, in a "fast" life cycle, new eggs may be passed in the faeces onto the pasture within 5-6 weeks. The rate of development from the first larval stage (L1) to L3 stage is directly proportionate to temperature: in warm weather, eggs can hatch and yield infective L3 in as little as 3 days. Once they reach the L3 stage, they become surrounded by a protective membrane, and can survive well even in freezing conditions, which means that they have the ability to remain on the pasture for a prolonged period. In the case of experimental infections, the development time of infections could be influenced by chilling the larvae, or by administering a trickle infection rather than a single infection. In the case of a single infection, the mean pre-patent period was 53 days with a range of 48 to 62 days, while with trickle infection the mean pre-patent period was 65 days with a range of 60 to 77 days [14].

Moreover, cyathostomins differ from other worm species in that the maturation of the early third larval stage (EL3) might be arrested for a prolonged period of time. After ingestion, the L3 ex-sheath and invades the mucosa of the large intestine. Once inside, the larval stages protect themselves by becoming encysted. In fact, up to $90 \%$ of encysted cyathostomins may become "inhibited" in their EL3 stage of development [4], and can remain within the intestinal wall for periods ranging from about 4 months to as long as 2 years.

The season during which inhibition occurs varies dependent on climate. In temperate climates accumulation of larvae will occur during the grazing season, the larvae will encyst during the cooler months of the year, and may emerge en-masse as the weather warms up in spring. The reverse timing is seen in tropical climates, where the most likely timing for inhibition is during the stressful, hot summer months, with larval emergence in autumn [15].

Therefore, small strongyles have the ability to survive both on the pasture and inside the horse for very long periods of time, and effective, sustainable management and treatment programmes need to take into consideration the climatic conditions and lifecycle.

The important epidemiological risk factors for infection with cyathostomins have been identified as age, season and time since last deworming [16]. Interestingly, access to grazing and shared grazing with other horses were only weakly associated with cyathostominosis.

\section{Species prevalence}

While the classification of small strongyle species of horses has been the subject of some discussion, there is general agreement that more than 50 species may be involved in parasitism of horses. Identification of species is usually performed on adult rather than larval stages, although in more recent times in vitro testing based on genotype has been developed [17].

Information is available on the most prevalent species of cyathostomins from a number of continents $[3,5,7,9,18]$ and from differing climatic regions within continents. Often, cyathostomins were present in the majority of horses surveyed (>70\% to $100 \%$ ) with multiple species present in individual animals. The number of species ranged from a few to up to 26 , but there was a remarkable similarity in the predominant species, regardless of geography. For example, Cyathostomum catinatum, Cylicocyclus nassatus and Cylicostephanus longibursatus were found to be amongst the most prevalent five species in France, Ukraine, US and Australia. C. nassatus was also common in Brazil. Other species that were widely recognized included Cylicostephanus minutus, Cylicostephanus calicatus and Cyathostomum insigne. Ambient temperature does not appear to be a significant factor in species distribution, as the mix of species reported from tropical and temperate climatic zones in Australia was very similar $[3,9]$. 
Little is understood about the relative pathogenicity of individual species, or what determines the balance of species in any mixed population. Some species are known to predominantly reside in the colon, while others seem to prefer the caecum [19]. Little is also known about individual species' lifecycles in terms of patency period, although it has been reported that those species residing in the caecum appear later in the faeces than species residing in the colon [20].

\section{Clinical significance}

Small strongyles also have a remarkable ability to be pathogenic to the horse from the moment that they enter its gut. In common with other nematodes, large numbers of adult worms may cause clinical symptoms such as lethargy, sudden weight loss, debilitation, and diarrhoea. However, cyathostomin larval stages can cause even more serious problems. At the start of their invasion, the exsheathed L3 may cause serious damage to the intestinal mucosa. Once at the encysted stage, tens of thousands of encysted larvae may literally cover the mucosa wall, severely damaging it and greatly reducing nutritional metabolism [5]. The wall of the cyst protects the larva, and thus it may be unaffected by conventional dewormers.

But the most devastating damage can arise from the developed L4 stage when it emerges from the cyst and continues its development to the adult stage in the intestinal lumen. This usually occurs in the late winter or early spring, when enormous numbers of larvae emerge into the gut lumen en masse. This condition, known as "larval cyathostominosis", can severely damage the gut wall, with a resultant diarrhoea, potentially serious colic, and a mortality rate as high as 50\% [21-29]. Granulomatous colitis has also been reported associated with small strongyle larvae [30].

Although young horses are most vulnerable [6], it is important to note that there is a lifelong susceptibility to cyathostomins, and that they can cause clinical disease in any age of horse during any season [31]. Because cyathostomins can be pathogenic both at penetration into and emergence from the large intestinal mucosa, it is essential that both incoming and encysted larvae are effectively eliminated. In the case of the encysted cyathostomins, their potentially long arrested development may be influenced by a larger larval challenge dose and how many grazing seasons have been experienced [31].

\section{Clinical and histo-pathological diagnosis}

Since the clinical signs and clinical pathology associated with cyathostomins are not specific and are similar to a number of other conditions, diagnosis can be challenging. However, a rapid diagnosis is a necessity if appro- priate treatments are to be administered with due speed, as this can be a condition with high mortality. Unfortunately, many times a diagnosis may only be arrived post mortem [32]. Affected horses may be of any age and present with any of the following signs: chronic diarrhoea, oedema, anorexia, dullness, acute weight loss pyrexia $[24,33]$. Similarly haematology is not diagnostic.

A typical clinical picture includes neutrophilia, hypoalbuminaemia, hyperglobulinaemia, especially betaglobulin, all are findings that are consistent with a protein-losing enteropathy. Low total serum protein has been reported, as well as slightly high total protein $[33,34]$, possibly a result of dehydration. Diagnosis based on clinical and haematological findings includes a horse presenting in poor condition with diarrhoea, a serum albumin concentration of less than $20 \mathrm{~g} / \mathrm{L}$ and a ratio of albumin:globulin of less than 0.7. Such a case is very likely to be infected with adult and L4 stages of cyathostomins [35]. There may be anaemia with or without eosinophilia and/or lymphocytosis [22] One useful diagnostic finding is the presence of large numbers of cyathostomin larvae in faeces, but their absence does not necessarily rule out cyathostomins as a cause of the clinical condition [21,35].

Necropsy findings show inflammation of colon and/or caecum, in the acute stage there is marked mucosal hyperaemia, haemorrhage, congestion, ulceration or necrosis. In more chronic cases there may be only some mucosal thickening due to oedema, and irregular areas of congestion. Numerous small strongyle larvae can be seen in the mucosa on careful inspection. Transillumination using a powerful lights source from the serosal surface will aid their detection [21].

On histopathology, a cellular and inflammatory response will be seen including mixed populations of mononuclear cells, eosinophils and epithelial cells. The response may focus around the larvae in the submucosa, or may be more diffuse involving the mucosal lamina propria as well as the submucosa [21].

\section{Current control measures}

Without a doubt, managing the level of small strongyle challenge, particularly the avoidance of the larval cyathostominosis syndrome, is the preferred path. Treatment of clinical cases can be protracted, difficult and unrewarding, with mortality rates of $40-70 \%$ reported even with aggressive treatment.

The plethora of publications describing possible control measures are a testament that control is difficult, that there is no one programme that can be used under all circumstances but that control practices need to be 
tailored to individual horse farms and yards. Control measures inevitably involve the use of anthelmintics, however, the ever increasing prevalence of resistance adds another level of difficulty to designing appropriate control programmes.

It is therefore advisable to use an anthelmintic with a high efficacy that will substantially reduce larval pasture burdens, and one which is proven to be effective against encysted cyathostomins. It is only with the best weapons and an effective strategy that the challenge of combating these highly pathogenic invaders can be achieved.

Over the past 20 years, management of cyathostomins has relied heavily on the repeated use of anthelmintic drugs. Various drug treatment regimens have been recommended, often recommending set interval treatments without regard to drug properties, age of horses [36,37] or epidemiology of the cyathostomins, and attempts have been made to address better control strategies [38-43].

The objectives of effective control programmes should address measures to reduce the numbers of infective larvae on pastures and to reduce the number of anthelmintic treatments required to achieve this egg reduction as a means of delaying or avoiding drug resistance in the cyathostomin population [44].

There are three available drug classes for cyathostomin control in horses, the benzimidazoles such as fenbendazole and oxfendazole, the tetrahydropyrimidines which are the pyrantel salts, and the macrocyclic lactones (ML), ivermectin and moxidectin. All of these drugs have differing levels of efficacy, duration of activity and spectrum of stages of cyathostomins they control. The ML class of drugs has become ever more widely used due to their potency, spectrum of activity, relative safety, and as yet few reports of resistance.

In the case of fenbendazole, the recommended dose of $5 \mathrm{mg} / \mathrm{Kg}$ liveweight will control sensitive strains of adult and developing larval stages of small strongyles. For control of inhibited stages a daily dose of $10 \mathrm{mg} / \mathrm{Kg}$ liveweight for 5 consecutive days is recommended. Fenbendazole resistance has been recognised as being widespread in all major horse populations surveyed and use of this compound at either dosage regimen should be avoided where resistance occurs [45-51].

Treatment regimens with pyrantel salts have varied, and include recommendations for monthly treatments, or even daily administration which was adopted in horse operation the US for many years, although this programme did not find favour in other geographies.
Pyrantel salts are not effective against inhibited stages of small strongyles but will remove sensitive strains of adults. Resistance to pyrantel salts has been identified both in Europe and the US, but does not appear to be as widespread as resistance to benzimidazoles [52-57].

As a general caution, unless sensitivity has been demonstrated by a faecal egg count reduction test, use of benzimidazole or pyrantel based anthelmintics carries the risk that treatment will be ineffective [58-61].

The two compounds within the macrocyclic lactone group need to be considered separately due to significant differences in potency and spectrum. The first available ML for horse, ivermectin, is highly potent against adult stages, luminal larval stages and developing stages of larvae in mucosa, but has variable and low efficacy against inhibited stages, even when elevated doses (5X) are administered [62-64].

Moxidectin, in addition to having high efficacy against all cyathostomin stages given as a single dose at a rate of $0.4 \mathrm{mg} / \mathrm{Kg}$ liveweight [62-66] also provides persistent activity against re-infection by small strongyles [67], resulting in a long egg re-appearance interval. The required re-treatment interval with moxidectin is longer than that for other anthelmintics allowing less frequent treatment and less selection for resistance $[44,57,68-75]$.

The effects of removal of luminal stages of parasites on emergence of inhibited stages, whether by anthelmintic treatment or natural expulsion, must also be taken into account when designing new approaches to cyathostomin control programmes [76]. Another factor of importance to clinicians is the consequence of killing the inhibited stages, as it has been reported that the die-off of these stages following fenbendazole treatment results in severe inflammation of the mucosa of the colon. In the same study, inflammation was not seen subsequent to the elimination of these stages using moxidectin [77].

\section{Conclusion}

We are fortunate that the last two decades have seen a large body of research, information and understanding of the complex issues surrounding the life cycle, clinical significance and control of small strongyles in horses. We have the opportunity to apply this knowledge to develop better control programmes than have been implemented in the past.

Monahan summed the situation well by stating in 2000: "Rote memorization of treatment schedules and antiparasitic drugs without understanding the biology of the worms to be controlled concedes any intellectual advantage to the worms" [44]. 


\section{Competing interests}

The author declares no conflicting interests in the preparation or content of this review.

\section{Acknowledgements}

This article is published as part of Parasites \& Vectors Volume 2 Supplement 2,2009 . This supplement includes the Proceedings of the "Workshop on equine cyathostomins, the most important parasitic helminth of horses: epidemiology, clinical significance, drug resistance and control" that was held at the University of Teramo, Italy on 20th May, 2009. Additional articles cover other equine nematode parasites, new developments in diagnostic techniques and proposals for more effective sustainable control programmes. The full contents of this supplement are available online at http://www.parasitesandvectors.com/supplements/2/S2.

Publication of this supplement has been sponsored by Fort Dodge Animal Health.

\section{References}

I. Lyons E, Tolliver S, Drudge J: Historical perspective of cyathostomes: prevalence, treatment and control programs. Vet Parasitol 1999, 85:97-II2.

2. Smets K, Shaw D, Deprez D, Vercruysse J: Diagnosis of larval cyathostominosis in Belgium. Vet Rec 1999, 144:665-668.

3. Mfitilodze M, Hutchinson G: Prevalence and abundance of equine strongyles (Nematoda: Strongyloidea) in tropical Australia. J Parasitol 1990, 76:487-494.

4. Proudman C], Matthews JB: Control of Intestinal Parasites in Horses. In Practice 2000, 22:90-97.

5. Collobert-Laugier C, Hoste H, Sevin C, Dorchies P: Prevalence, abundance and site distribution of equine small strongyles in Normandy, France. Vet Parasitol 2002, I I 0:77-83.

6. Love S, Murphy D, Mellor D: Pathogenicity of cyathostome infection. Vet Parasit 1999, 85: I I3-122.

7. Souto-Maior M, Alves L, Mota R, Carvalho-Junior G, Barbosa C: AAVP Proceedings 45th Annual Meeting, p 36.

8. Herd R: The changing world of worms: The rise of the cyathostomes and the decline of Strongylus vulgaris. The Compendium for Continuing Education of the Practicing Veterinarian Equine 1990, p732-736.

9. Bucknell D, Gasser R, Beveridge I: The prevalence and epidemiology of gastrointestinal parasites of horses in Victoria, Australia. Int J Parasitol 1995, 25:71 I-724.

10. Linc $E$, Hoglund J, Ljungstrom $B$, Nilsson $O$, Uggla A: A field survey on the distribution of strongyle infections of horses in Sweden and factors affecting faecal egg counts. Equine Vet $J$ 1999, 31:68-72.

II. Peregrine A, McEwen B, Bienzle D, Kock T, Weese J: Larval cyathostominosis in horses in Ontario: An emerging disease. Can Vet J 2006, 47:80-82.

12. Chapman M, French D, Klei T: Gastrointestinal helminths of ponies in Louisiana: A comparison of species currently prevalent with those present $\mathbf{2 0}$ years ago. Journal of Parasitology 2002, 88: II $130-1134$

13. Lyons E, Swerczek T, Tolliver S, Bair H, Drudge J, Ennis L: Prevalence of selected species of internal parasites in equids at necropsy in central Kentucky. Vet Parasitol 2000, 92:5I-62.

14. Love S, Duncan J: Development of cyathostome infection of helminth naïve foals. Equine Vet Journal I992, Suppl I 3:93-98.

15. Baudena M, Chapman M, French D, Klei T: Seasonal development and survival of equine cyathostome larvae on pasture in south Louisiana. Vet Parasitol 2000, 88:5I-60.

16. Von Samson-Himmelstjerna G, von Witzendorff C, Sievers G, Schneider T: Comparative use of faecal egg count reduction test, egg hatch assay and beta-tubulin codon 200 genotyping in small strongyles (cyathostominae) before and after benzimidazole treatment. Vet Parasitol 2002, 1 08:227-235.

17. Traversa D, lorio R, Klei T, Kharchenko V, Gawor J, Otranto D, Sparagno O: New method for simultaneous species-specific identification of equine strongyles (nematode, strongylida) by reverse line blot hybridization. Journal of Clinical Microbiology 2007, 45:2937-2942.
18. Dvojnos G, Kharchenko V: Morphology and differential diagnostics of parasitic larvae of some strongylidae nematode of horses. An Parasitol, 1990, 3 I:I5-28.

19. Reinemeyer C, Herd R, Gabel A: Distribution of adult and larval cyathostomes in helminth naïve foals after primary infection. Equine Vet Journal 1988, 20:296-297.

20. Kuzmina T, Kharchenko V, Starovir A, Dvojnos G: Analysis of the strongylid nematodes (Nematoda: Strongylidae) community after deworming of brood horses in Ukraine. Vet Parasitol 2005, | 3 I:283-290.

21. Abbott E: Larval cyathostomosis: The disease, its diagnosis and treatment. Equine Practice 1998, 20:6-7.

22. Giles C, Urquhart K, Longstaffe J: Larval cyathostomiasis (immature trichonema-induced eneteropathy): A report of 15 clinical cases. Equine Vet Journal 1985, I7:196-20I.

23. Love S: Parasite-associated equine diarrhea. The Compendium 1992, 14:642-648.

24. Lyons E, Swerczek T, Tolliver S, Drudge J, Stamper S, Grandstrom D, Holland R: A study of natural infections of encysted small strongyles in a horse herd in Kentucky. Vet Med 1994, II46II 55.

25. Mair T: Outbreak of larval cyathostomiasis among a group of yearling and two year old horses. Vet Record 1994, 135:598-600.

26. Mair T, Pearson G: Multifocal non-strangulating intestinal infarction associated with larval cyathostomiasis in a pony. Equine Vet J 1995, 27: I54-I55.

27. Matthews A, Morris J: Cyathostomiasis in horses. Vet Record 1995, 136:52.

28. Reilly G, Cassidy J, Taylor S: Two fatal cases of diarrhea in horses associated with larvae of small strongyles. Vet Record 1993, 132:267-268.

29. Vitellozzi G, Fioretti D: Gross and histopathological findings in the large intestine of healthy slaughter horses and their correlation with cyathostome infection. Acta Medica Veterinaria 1991, 37:159-170.

30. Chapman M, French D, Taylor H, Klei T: One season of pasture exposure fails to induce a protective resistance to cyathostomes but increases numbers of hypobiotic thirdstage larvae. Journal of Parasitology 2002, 88:678-683.

3I. Jasko D, Roth L: Granulomatous colitis associated with small strongyle larvae in a horse. JAVMA 1984, I 85:553-554.

32. Kelly J, Fogarty U: Outbreak of larval cyathostomiasis on a thoroughbred stud farm. Irish Veterinary Journal 1993, 46:133-136.

33. Love S, Mair T, Hillyer M: Chronic diarrhea in adult horses: a review of 5 I referenced cases. Vet Record 1992, 130:2 17-2 I9.

34. Love S, Escala J, Duncan J, McLean J: Studies on the pathogenic effects of experimental cyathostome infections in ponies. Proceedings of Sixth International Conference, Equine Infectious Diseases 1991, p I 49-155.

35. Smets K, Shaw D, Deprez J, Vercruysse J: Diagnosis of larval cyathostominosis in horses in Belgium. Vet Record 1999, I 44:665-668.

36. Herd R, Gabel A: Reduced efficacy of anthelmintics in young compared with adult horses. Equine Vet Journal 1990, 22:164-169.

37. Matthee S: Anthelmintic treatment in horses:The extra-label use of products and the danger of under-dosing. Journal of the South African Veterinary Medical Association 2003, 74:53-56.

38. Paul J: Optimal internal parasite control for horses with emphasis on larval cyathostomosis. Large Animal Practice 1999, 20:33-36.

39. Reinemeyer C: Equine small strongyles: Unanswered questions. The Compendium - Equine Forum 1992, p 816-819.

40. Heile C, Schein E: Strategic parasite control in horses: an overview, Part I, endoparasites. Praktische Tierartz 2004, 85 J:890-897.

4l. Herd R: Equine parasite control - problems associated with intensive anthelmintic therapy. Equine Veterinary Education 1990, 2:4I-47.

42. Hutchens D, Paul A, DiPietro J: Treatment and control of gastrointestinal. Vet Clin North Amer Equine Pract I 1:56I-563.

43. Uhlinger C: Equine small strongyles: Epidemiology, pathology and control. Compendium on Continuing Education for the Practicing Veterinarian 1991, 13:863.

44. Monahan C]: Anthelmintic Control Strategies for Horses. Companion and Exotic Animal Parasitology 2000. International veterinary Information Service www.ivis.org. 
45. Varady $M$, Konigova $A$, Corba J: A field study to evaluate the efficacy of fenbendazole on 9 stud farms. Veterinarni Medicina 2004, 49:42-46.

46. Collobert C, Bernard N, Clement F, Hubert J, Kerboeuf D, Flochlay A, Blond Riou F: Efficacy of oral moxidectin gel against benzimidazole-resistant cyathostomes in horses both naturally and artificially infected with a field population. $J$ Equine Vet Science 1998, I 8:9588-9590.

47. Eysker M, Boersma, Kooyman F: Effect of repeated oxfendazole treatments on small strongyle infections in Shetland ponies. Res Vet Science 1989, 46:409-4I2.

48. Rolfe P, Dawson K: The efficacy of a combination anthelmintic against oxibendazole resistant small strongyles, large strongyles and ascarids in horses. Aust Vet / 1994, 71:304-306.

49. Schillinger $D$, Hasslinger $M$ : Benzimidazole resistance in smal strongyles of horses - occurrence in Germany and strategies for avoiding resistance. Rev Med Vet 1994, I 45: I | 9- I 24

50. Lloyd S, Smith J, Connon R, Hatcher M, Hedges T, Humphrey D, Jones $A$ : Parasite control methods used by horse owners: Factors predisposing to the development of anthelmintic resistance in nematodes. Vet Record 2000, 146:487-492.

51. Lendal S, Marsen M, Bjorn H, Craven J, Chriel M, Olsen S: A questionnaire survey on nematode control practices on horse farms in Denmark and the existence of risk factors for the development of anthelmintic resistance. Vet Parasitol 1998 78:49-63.

52. Herd R, Majewski G: Comparison of daily and monthly pyrantel treatment in yearling thoroughbreds and the protective effect of strategic medication of mares and their foals. Vet Parasitol 1994, 55:93-104.

53. Slocombe O, de Gannes R: Cyathostomes in Canada resistant to pyrantel salts and effectively removed by moxidectin. Vet Parasitol 2006, I40:181-184.

54. Monahan C, Chapman M, Taylor H, French D, Klei T: Experimental cyathostome challenge of ponies maintained with or without benefit of daily pyrantel tartrate feed additive: Comparison of parasite burdens, immunity and colonic pathology. Vet Parasitol 1998, 74:229-24I.

55. Monahan C, Chapman M, Taylor H, French D, Klei T: Foals raised on pasture with or without daily pyrantel tartrate feed additive: Comparison of parasite burdens and host responses following experimental challenge with large and small strongyle larvae. Vet Parasitol 1997, 73:277-289.

56. Osterman E, Nilsson O, Hoglund J, Uggla A: Treatment intervals for ivermectin and pyrantel: Treatment of strongylids in horses. Svensk Veterinartidning 1996, 48:28I-284.

57. Taylor S, Kenny J: Comparison of moxidectin with ivermectin and pyrantel embonate for reduction of faecal egg counts in horses. Vet Record 1995, 137:516-518.

58. Boersma J, Borgsteede F: The prevalence of anthelmintic resistance of horse strongyles in the Netherlands. Veterinary Quarterly 1991, 13:209-217.

59. Fisher M, Jacobs D: Prevalence of benzimidazole resistance in equine cyathostome populations in southeast England. Vet Record 1993, 130:315-318.

60. Herd R, Coles G: Slowing the spread of anthelmintic resistant nematodes of horses in the United Kingdom. Vet Record 1995 136:48|-485.

61. Kaplan R: Anthelmintic resistance in nematodes of horses. Vet Research 2002, 33:491-507.

62. Reinemeyer C, Farley A: Comparison of cyathostome control and selection for benzimidazole resistance using moxidectin gel or Panacur Powerpac paste. AAVP Proceedings, 2002, $47^{\text {th }}$ Annual Meeting.

63. Eysker M, Boersma J, Kooyman F: The effect of ivermectin treatment against inhibited early third stage, late third stage and fourth stage larvae and adult stages of the cyathostomes in Shetland ponies and spontaneous expulsion of these helminths. Vet Parasitol 1992, 42:295 -302.

64. Xiao L, Herd R: Comparative efficacy of moxidectin and ivermectin against hypobiotic and encysted cyathostomes and other equine parasites. Vet Parasitol 1994, 53:83-90.

65. Monahan C, Chapman M, Taylor H, French D, Klei T: Comparison of moxidectin oral gel and ivermectin paste against a spectrum of internal parasites of ponies with special attention to encysted cyathostome larvae. Vet Parasitol 1996, 63:225-235.

66. Bello T, Lanigan J: A controlled trial evaluation of three oral dosages of moxidectin against equine parasites. J Equine Vet $\mathrm{Sci}$ $1994,4: 483-488$.

67. Vercruysse J, Eysker M, Demeulenaere D, Smets K, Dorny P: Persistence of the efficacy of moxidectin gel on the establishment of cyathostominae in horses. Veterinary Record 1998, 143:307-309.

68. Corba J, Praslicka J,Varady M,Andrasko H, Holakovsky P: Efficacy of moxidectin 2\% equine gel and EQVALAN I\% paste against parasitic nematodes of horses. Helminthologia 1995, 32:21 5-218.

69. Costa A, Barbosa O: Comparative efficacy of moxidectin ge and ivermectin paste against parasitic nematodes of horses. Rev Bras Parasitol 1995, 4: I |4.

70. Costa A, Barbosa O, Moraes F, Acuna A, Rocha U, Soares V: Comparative efficacy evaluation of moxidectin gel and ivermectin paste against internal parasites of equines in Brazil. Vet Parasitol 1998, 80:29-36.

71. Jacobs D, Hutchinson $M$ : Equine cyathostome infection: Suppression of faecal egg output with moxidectin. Vet Record 1995, I37, p 545

72. Schumacher J, Taintor J: A review of the use of moxidectin in horses. EquineVet Educ 2008, 20:546-55I.

73. Solari Basano F, Chierichetti N, Genchi C: Use of moxidectin and ivermectin in cyathostominae yearly control plan. Comparison of efficacy and persistency in naturally infected horses. Parassitologia 1998, 40:168.

74. Slocombe $O$, Lake $M$ : Return of strongyle eggs in feces of equids in Ontario after treatment with moxidectin or ivermectin. Proceedings AAVP 1996, Abstract \#3I.

75. Zeeuw G, Hasslinger $M$ : Vergleichende untersuchungen zu eizahlreduktion und behandlungs - interval bei endoparasiten des pferdes. Der Praktische Tierarzt 1997, 78:857-864.

76. Eysker M, Boersma J, Kooyman F: Emergence from inhibited development of cyathostome larvae in ponies following failure to remove them by repeated treatments with benzimidazole compounds. Vet Parasitol 1989, 34:87-93.

77. Steinbach T, Bauer C, Sasse H, Baumgartner W, Rey-Moreno C Hermosilla C, Damriyasa I, Zahner H: Small strongyle infection: Consequences of larvicidal treatment of horses with fenbendazole and moxidectin Vet Parasitol 2006, |39:| | 5-|3| 